bodies in Parkinson's disease, indicate that aberrations in the folding, processing and degradation of proteins lead to neuronal degeneration.

Elisabeth Leroy ${ }^{\star}$, Rebecca Boyer ${ }^{\star}$, Georg Auburger ${ }^{\star} \dagger$, Barbara Leube $\dagger$, Gudrun Ulm $\neq$ Eva Mezey§, Gyongyi Harta\$, Michael J. Brownstein|, Sobhanadditya Jonnalagadag, Tanya Chernovag, Anindya Dehejia*, Christian Lavedan*, Thomas Gasser\#,

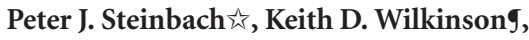
Mihael H. Polymeropoulos*

${ }^{*}$ Genetic Disease Research Branch, NHGRI, NIH, Building 49 Room 4A66, Bethesda, Maryland 20892, USA

$\dagger$ Department of Neurology, University Hospital, PO Box 101007, 40001 Düsseldorf, Germany

$\ddagger$ Paracelcus-Elena-Klinik, 34128 Kassel, Germany $\$$ Basic Neuroscience Program, NINDS,

NIH, Building 36 Room 3D06, Bethesda,

Maryland 20892, USA

||Section on Genetics, NIMH,

NIH, Building 36 Room 3D06,

Bethesda, Maryland 20892, USA

gDepartment of Biochemistry,

Emory University School of Medicine,

Atlanta, Georgia 30322, USA

\#Neurologische Klinik, Klinikum Grosshadern,

Ludwig-Maximilians-Universitat,

München, Germany.

\ Center for Molecular Modeling, CIT,

NIH, Building 12A Room2041, Bethesda,

Maryland 20892, USA

1. Polymeropoulos, M. H. et al. Science 276, 2045-2047 (1997).

2. Kruger, R. et al. Nature Genet. 18, 106-108 (1998).

. Spillantini, M. G. et al. Nature 388, 839-840 (1997)

4. Wilkinson, K. D. et al. Science 246, 670-673 (1989)

Wilkinson, K. D., Deshpande, S. \& Larsen, C. N. Biochem. Soc. Trans. 20, 631-637 (1992).

6. Lowe, J., McDermott, H., Landon, M., Mayer, R. J. \& Wilkinson, K. D. J. Pathol. 161, 153-160 (1990).

7. Larsen, C. N., Krantz, B. A. \& Wilkinson, K. D. Biochemistry 37, 3358-3368 (1998).

8. Larsen, C. N., Price, J. S. \& Wilkinson, K. D. Biochemistry 35, 6735-6744 (1996).

9. Dang, L. C., Melandri, F. D. \& Stein, R. L. Biochemistry 37, 1868-1879 (1998).

\section{Whale ankles and evolutionary relationships}

There are two main hypotheses for the relationships of the mammalian order Cetacea (comprising whales, dolphins and porpoises). The first hypothesis, mainly supported by DNA sequence data ${ }^{1,2}$, is that one of the groups of artiodactyls (for example, the hippopotamids) is the closest extant relative of whales and that Artiodactyla are paraphyletic if Cetacea are excluded from it. The second hypothesis, mainly supported by palaeontological data ${ }^{3,4}$, identifies mesonychians, a group of extinct archaic ungulates, as the sister group to whales. These two hypotheses are not mutually exclusive, because mesonychians and cetaceans could be sister groups, and this combined clade (Cete) could be the sister group to a group of artiodactyls.

The morphology of the ankle can be used to evaluate these hypotheses. Ankle specializations are universally used to characterize Artiodactyla, and would provide an excellent test for the inclusion of whales in that order. Unfortunately, the few cetacean ankle bones known are too incomplete or too reduced to allow meaningful comparison with other mammals.

We have recently recovered fragmentary Eocene astragali (ankle bones) from pakicetid and ambulocetid cetaceans ${ }^{5}$ in Pakistan. We identified them as cetaceans because the deeply grooved trochlea resembles the partial astragalus of the holotype of Ambulocetus natans, and the large size of the astragali matches only a few mammals known from the associated freshwater and marine faunas, in particular perissodactyls, anthracobunids and sirenians. Astragali for known representatives or relatives of these mammals do not match the morphology of the new bones. The ambulocetid astragalus was found in marine sediments.

Three articular facets of artiodactyl ankles are highly specialized and are important for the relationship of whales. First, the astragalar head of artiodactyls is trochleated, meaning that it is wide, gently concave mediolaterally, and strongly convex dorsoplantarly, with the axis of this convexity perpendicular to the median plane. Second, the sustentacular facet is rectangular and covers the entire posterior aspect of the astragalus. Finally, the ectal (posterior calcaneo-astragalar) facet is reduced and placed on the lateral side of the bone. The combination of these features is found in all artiodactyls but not in any other mammal.

The cetacean astragalar head (Fig. 1) is
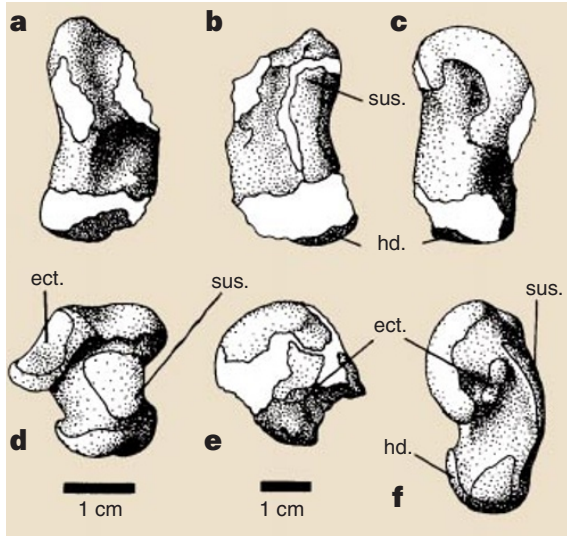

Figure 1 Astragali of: a-c, ?pakicetid cetacean shown in dorsal (a), plantar (b) and medial (c) view (H-GSP 97227, Locality 300); d, mesonychian (plantar view, Disaccus europaeus, MNHN Br 21 L); e, ?ambulocetid cetacean (lateral view, H-GSP 97113, Locality 9205, distal part missing); and f, artiodactyl (lateral view, Sus scrofa). Shown are ectal facet (ect.), sustentacular facet (sus.) and astragalar head (hd.). Left scale bar is for $\mathbf{a}-\mathbf{d}$, right scale bar is for $\mathbf{e - f}$. wide and nearly flat both mediolaterally and dorsoplantarly. This is unlike the condyle of mesonychians, but is also unlike the convex trochleated head of artiodactyls. This important feature, often cited as the main defining character of artiodactyls ${ }^{6}$, is inconsistent with the hypothesis that cetaceans should be included in the artiodactyls.

The cetacean sustentacular facet resembles that of artiodactyls in being long, but unlike that of artiodactyls it is narrow. In primitive mammals, including mesonychians, the sustentacular facet is short and rounded. The cetacean ectal facet is strongly reduced and placed laterally as in artiodactyls, not plantarly as in mesonychians and other primitive mammals. This position of the ectal facet is highly derived ${ }^{7}$ and unique, occurring only in artiodactyls and these Eocene cetaceans. These features argue against close phylogenetic ties between cetaceans and mesonychians.

Our new ankle data do not unambiguously support either of the predominant hypotheses of cetacean relationships. Inclusion of Cetacea in Artiodactyla to the exclusion of mesonychians is consistent with the position of the ectal facet and the shape of the sustentacular facet. But the absence of a trochleated astragalar head argues against the inclusion of Cetacea in Artiodactyla, unless the flat head of the cetacean is interpreted as a secondary aquatic adaptation. Inclusion of Cetacea in Artiodactyla is also inconsistent with the derived similarities of the dentition and basicranium of cetaceans and mesonychians ${ }^{8}$. Sister-group relations between mesonychians and cetaceans are inconsistent with the derived similarities in the sustentacular and ectal facets between artiodactyls and cetaceans, both characters with little or no homoplasy in mammals. But, in any case, extensive convergence or reversals must have occurred in the dentition, basicranium and/or tarsus.

\section{J. G. M. Thewissen}

Department of Anatomy,

Northeastern Ohio Universities, College of Medicine, Rootstown, Ohio 44272, USA

\section{S. I. Madar}

Department of Biology, Hiram College,

Hiram, Ohio 44234, USA

\section{S. T. Hussain}

Department of Anatomy,

Howard University, College of Medicine,

Washington DC, 20059, USA

1. Gatesy, J., Hayashi, C., Cronin, M. \& Arctander, P. Mol. Biol. Evol. 13, 954-963 (1996).

2. Shimamura, M. et al. Nature 388, 666-670 (1997).

3. Van Valen, L. Am. Mus. Nat. Hist. Bull. 132, 1-126 (1966).

4. Thewissen, J. G. M. J. Mamm. Evol. 2, 157-184 (1994).

5. Thewissen, J. G. M., Madar, S. I. \& Hussain, S. T. Cour. Forsch. Inst. Senck. 191, 1-86 (1996)

6. Gentry, A. W. \& Hooker, J. J. in The Phylogeny and Classification of the Tetrapods Vol. 2. Mammals (ed. Benton, M. J.) 235-272 (Clarendon, Oxford, 1988).

7. Schaeffer, B. Am. Mus. Novit. 1356, 1-24 (1947).

8. Geisler, J. H. \& Luo, Z. in The Emergence of Whales (ed.

Thewissen, J. G. M. ) 163-212 (Plenum, New York, 1998). 